\title{
A Study on Child Working Population in India
}

\author{
Bhupen Barman ${ }^{1}$ and Nirmalendu Barman ${ }^{2}$ \\ ${ }^{I}$ Guest Lecturer in Geography, Rajganj College, Jalpaiguri, WB, India \\ ${ }^{2}$ Asst. Teacher, Geography, Nazrul Satavarshiki Vidyalaya, WB, India
}

\begin{abstract}
Present day the numbers of child working population are increasing day by day in the developing and under developed countries. Actually the child working populations are called as child labour whose age ranged from 5 to 14 years. In India, the children are engaged mostly in various low-key jobs of the unorganized sectors which are hazardous in situation. The Census found an increase in the number of child labourers from 11.28 million in 1991 to 12.66 million in 2001 and 21.39 million in 2011. In addition, nearly 85 per cent of child labourers in India are hard-to-reach, invisible and excluded, as they work largely in the unorganised sector, both rural and urban, within the family or in household-based units. This paper reveals the causes of increasing child working people as well as present condition and some suggestions about to reduce of child worker in different sector in the country.
\end{abstract}

Keywords: Child labour, hazardous jobs, Trafficking, Child labour Act.

\section{Introduction:}

Child working people are unequal in India. They are also called child labour. Any child out of school is a child labour .According to International Labour Organization (ILO); the term 'child labour' is often defined as work that deprives children of their childhood their potential and their dignity and that is harmful to physical and mental development. It refers to work that is mentally, physically, socially or morally dangerous and harmful to children; and interferes with their schooling by depriving them of opportunity to attend school; obliging them to leave school prematurely; or requiring them to attempt to combine school attendance with excessively long and heavy work". Child labour is recognized as a serious and enormously complex social problem in India. Children, under age 14 are often forced to work for as many as 18 hours a day. They are subject to malnutrition, impaired vision, deformities from sitting long hours in cramped over crowded work places; they become easy preys to deadly diseases like serious respiratory diseases, T.B., and Cancer. They are often forced to lead solitary lives away from their families, deprived of meaningful education and training opportunities that could prepare them for a better future. Child labour not only lead to a perpetual cycles of poverty for a family, it depresses the economy also. The immense benefits of abolition of child labour cannot be measured in economic terms alone, its enormous long term beneficial impact on the Society as a whole far outweighs the nominal economic hardship that some families would suffer only for a short span of time.

\section{OBJECTIVES:}

The following objectives has undertaken for the study;

i. $\quad$ To find out the causes, effect and present condition of child working people in India.

ii. To find out the present distribution of child working people in India.

iii. To suggest remedial measures to solve the problem of child working people.

\section{Methodology:}

For analysis this study is based on mainly secondary data on the different census issues of India and some data are collected from different journals, books, internet etc. Methodology applied in the study is totally depends on statistical analysis and represented by various cartographic techniques.

\section{DISTRIBUTION OF CHILD WORKING POPULATION:}

As per in the 1971 census report in India it may be found that 10753985 persons child working population are engaged in different jobs and it is observed that $15.13 \%$ of child labour was engaged in Andhrapradesh which was the highest child labour affected state of India and otherwise in that year in Lakshadweep was only $\mathbf{9 7}$ persons child working population which is lowest child labour affected state in India. .According to 1981 \& 1991 Census, the trend of child labour growth was similar as the census of 1971. It was changed in 2001 and 2011 where 12666377 and 21389196 persons child were working population in various low-key jobs \& highest number of child labourers found in Uttarpradesh. (See Table-1) 
Table-1

\begin{tabular}{|c|c|c|c|c|c|}
\hline \multicolumn{6}{|c|}{ State-Wise Distribution Of Working Children According To 1971,1981,1991 \& 2001 Census In The Age Group $5-14$ Years 4 years. } \\
\hline Sl. No & Name of the State/UT & 1971 & 1981 & 1991 & $2001 * * * *$ \\
\hline 1 & Andhra Pradesh & 1627492 & 1951312 & 1661940 & 1363339 \\
\hline 2 & Assam* & 239349 & $* *$ & 327598 & 351416 \\
\hline 3 & Bihar & 1059359 & 1101764 & 942245 & 111700 \\
\hline 4 & Gujarat & 518061 & 616913 & 523585 & 485530 \\
\hline 5 & Haryana & 137826 & 194189 & 109691 & 253491 \\
\hline 6 & Himachal Pradesh & 71384 & 99624 & 56438 & 107774 \\
\hline 7 & Jammu\& Kashmir & 70489 & 258437 & $* *$ & 175630 \\
\hline 8 & Karnataka & 808719 & 1131530 & 976247 & 822615 \\
\hline 9 & Kerala & 111801 & 92854 & 34800 & 26156 \\
\hline 10 & Madhya Pradesh & 1112319 & 1698597 & 1352563 & 1065259 \\
\hline 11 & Maharastra & 988357 & 1557756 & 1068427 & 764075 \\
\hline 12 & Chhattisgarh & & & & 364572 \\
\hline 13 & Manipur & 16380 & 20217 & 16493 & 28836 \\
\hline 14 & Meghalaya & 30440 & 44916 & 34633 & 53940 \\
\hline 15 & Jharkhand & & & & 407200 \\
\hline 16 & Uttaranchal & & & & 70183 \\
\hline 17 & Nagaland & 13726 & 16235 & 16467 & 45874 \\
\hline 18 & Odhisha & 492477 & 702293 & 452394 & 377594 \\
\hline 19 & Punjab & 232774 & 216939 & 142868 & 1772688 \\
\hline 20 & Rajasthan & 587389 & 819605 & 774199 & 1262570 \\
\hline 21 & Sikkim & 15661 & 8561 & 5598 & 16457 \\
\hline 22 & Tamil Nadu & 713305 & 975055 & 578889 & 418801 \\
\hline 23 & Tripura & 17490 & 24204 & 16478 & 21756 \\
\hline 24 & Uttar Pradesh & 1326726 & 1434675 & 1410086 & 1927997 \\
\hline 25 & West Bengal & 511443 & 605263 & 711691 & 857087 \\
\hline 26 & Andaman\& Nicobar Islands & 572 & 1309 & 12565 & 1960 \\
\hline 27 & Arunachal Pradesh & 17925 & 17950 & 12395 & 18482 \\
\hline 28 & Chandigarh & 1086 & 1986 & 1870 & 3779 \\
\hline 29 & Dadra\&Nagar Haveli & 3102 & 3615 & 4416 & 4274 \\
\hline 30 & Delhi & 17120 & 25717 & 27351 & 41899 \\
\hline 31 & Daman\&Diu & 7391 & 9378 & 941 & 729 \\
\hline 32 & Goa & & & 4656 & 4138 \\
\hline 33 & Lakshadweep & 97 & 56 & 34 & 27 \\
\hline 34 & Mizoram & $* * *$ & 6314 & 16411 & 26265 \\
\hline 35 & Pondicherry & 3725 & 3606 & 2680 & 1904 \\
\hline & Total & 10753985 & 13640870 & 11285349 & 12666377 \\
\hline
\end{tabular}

Note:* A 1971 census figure of Assam includes figures of Mizoram.

** Census could not be conducted.

*** Census figures 1971 in respect of Mizoram included under Assam.

**** includes marginal workers also

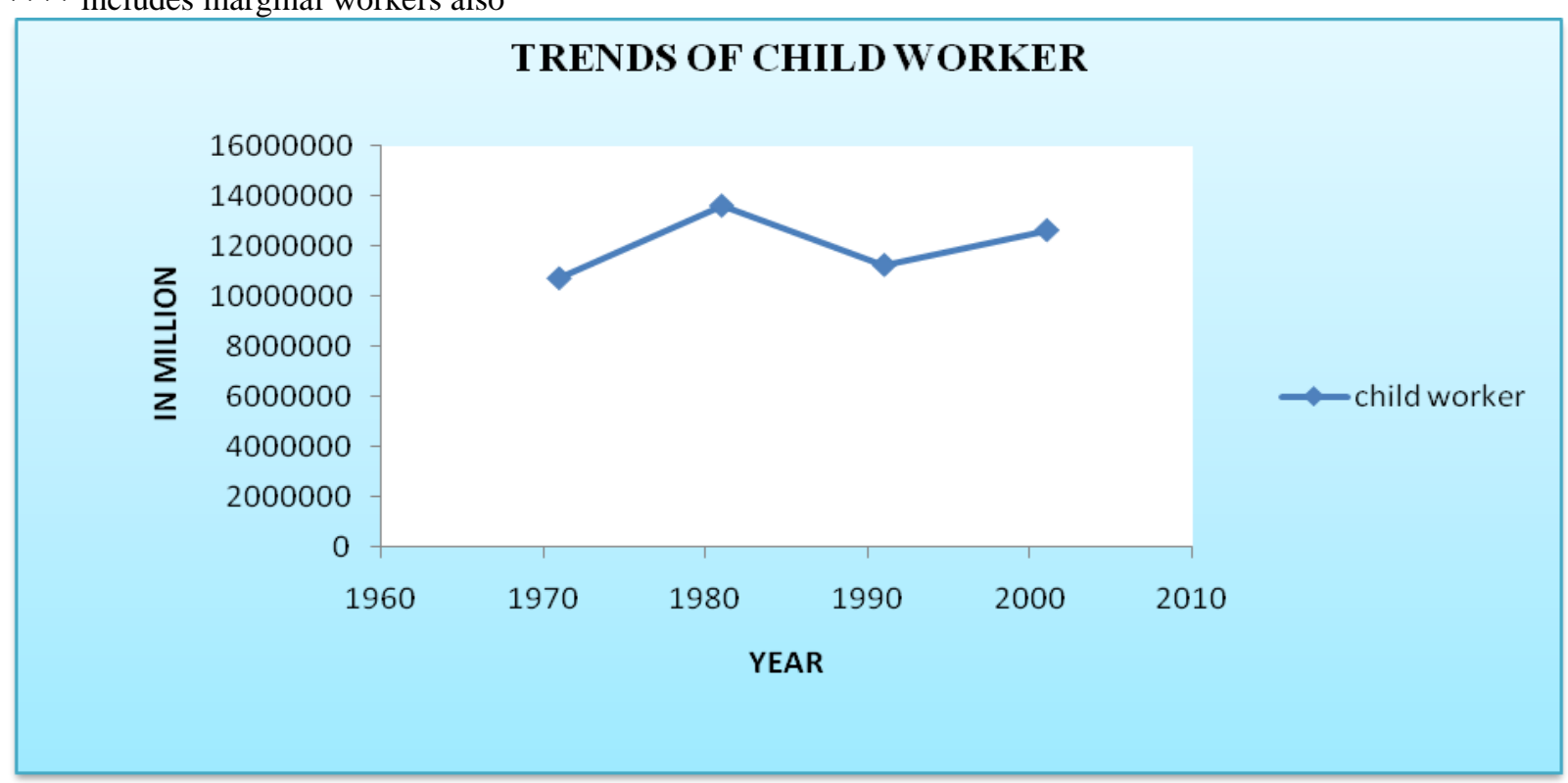

Fig-1; Trends of Child Working population in India 


\section{CONTROLLING FACTORS FOR DISTRIBUTION OF CHILD WORKER:}

Child labour is a pervasive problem though out the world, especially in developing countries. Child labours are especially prevalent in rural areas. Children work for variety reasons, such as-

a) Parental poverty is the principal controlling factor. The poverty of parents in rural area is widespread.

b) Landlessness contributes to poverty and poverty causes landlessness.

c) A majority of parents send their children to work rather than to school at the school going age, primarily on the account of their need for a supplementary income. It proved that the illiteracy of parents, absence of universal primary education, occupational rigidity of caste system (Ghosh, 2013).

d) Many parents prefer to send their children to work rather than to school on the account of availability of good job opportunities for their family livelihood.

e) Schooling problems also contribute to child labour. Many time children seek employment simply because there is no access to schools. When there is access, low quality often makes attendance a waste of time for the students. Schools in many developing areas suffer from problems such as overcrowding, inadequate sanitation and apathetic teachers.

f) Parental education plays a large role in determining child schooling and employment (Siddiqi \& Patrinos)

\section{DIFFERENT CHILD LABOUR ACTIVITIES:}

Fig. 3 shows the various child labour activities. According to 2001 census, India has 12666377(12.6 million) child workers. Fig.1 shows the changing trend of child labour population in India. This official figure makes India today largest number of child labourers under the age of 14 in the world. These children are employed in many industries, foot-wear, brick-kilns, stainless steel, hotels and restaurants etc. Here one important thing is that "hazardous" and "risks". A hazardous is anything with the potential to do harm. A risk is the livelihood of potential harm from that hazard being realized. The children were engaged in many works in export-oriented hazardous industries like carpet weaving. Gem polishing, glass blowing, match works, brass ware, electro plating, stone quarrying, lock making and beedi rolling etc. In this analysis it would be said that pull factors which is related to source income and push factors which is related to lack of income are the determinants of child labour in India

In the following some important informal sectors where the children are engaged in hazardous situation:

> Agrarian Sector- Children working long hours and under severe hardships on the fields. They are also exposed to the hazards of working with modern machinery and chemicals. These occupations as a part of family labour or as individual workers.

$>$ Industrial Sector- Like glass making, mining, construction, carpet weaving, brick making, fireworks and others as listed under the Child Labour Act.

$>$ Service Sector-In the different small and large service sector i.e., hotels and restaurants, Dhabas or bars, tourists spot, different shop establishments etc.

$>$ Prostitution Sector-Children are the blooming of the garden of the society and valuable asset of the nation. Childhood is considered as the most important of life. But now-days a large part of children are used in prostitution. Child prostitution involving both boys and girls is very common today but, female child prostitution is more common than male child prostitution. The trafficking of children for sexual exploitation is a high profit low risk trade for those who organize it, but it is detrimental to the millions of children exploited in slavery like conditions in the global sex industry (Ghosh, 2013). On basis of sexual trafficking (table;2) we have classified the destination of the countries in two ways:

Table; 2, SEXUAL TRAFFICKING COUNTRIES

\begin{tabular}{|l|l|}
\hline \multicolumn{1}{|c|}{ Primary destination countries } & \multicolumn{1}{c|}{ Secondary destination countries } \\
\hline Thailand & Brazil \\
Philippines & Cambodia \\
Sri Lanka & Columbia \\
Taiwan & Costa Rica \\
& India \\
& Italy \\
& Nepal \\
& South Africa \\
& Vietnam \\
\hline
\end{tabular}

Source: Trafficking in Human Being; International Conventions, Protocols and Charters, Susan Kreston, Fulbright Professor of Law \& Research Fellow, University of the Free State.

Trafficking is a global problem (fig-2). It is illegal transportation of forced labour, sex exploitation, forced marriages etc. Actually mainly affected women and children because of the poverty, lack of economic activities and less educational development. 


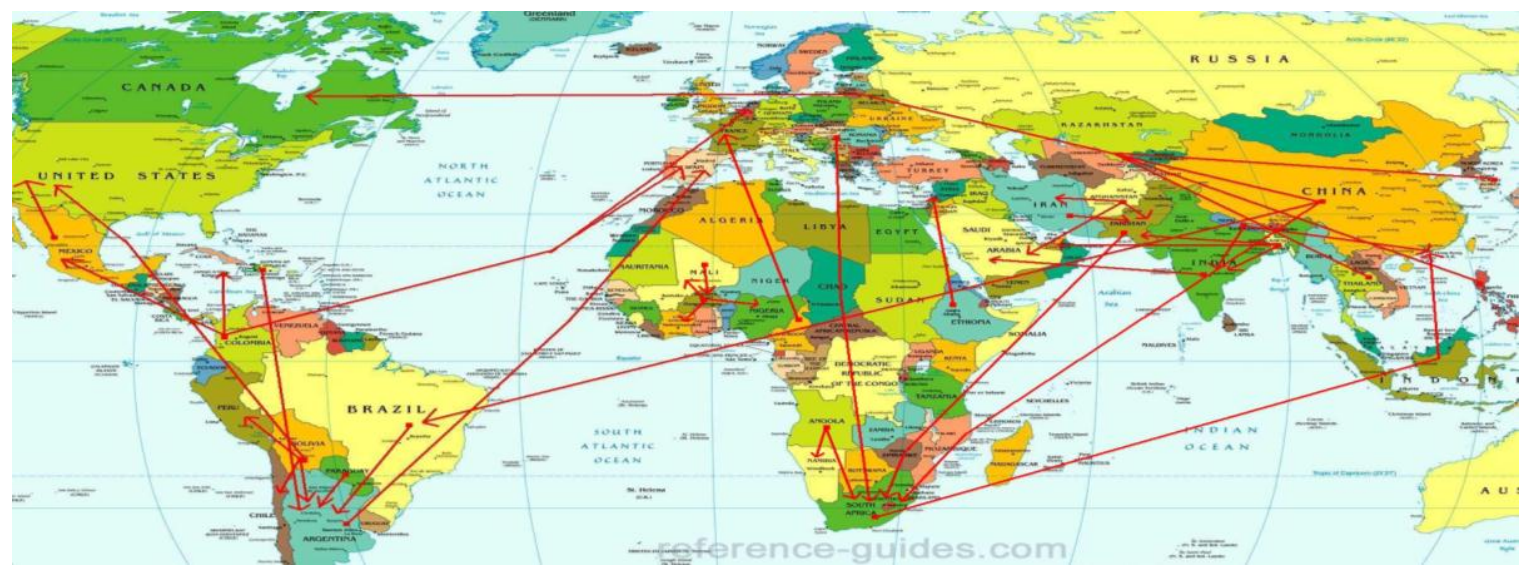

Fig-2; Trafficking in the World

$>$ Recreation Sector- In recreation the circus is one of the most ancient forms of indigenous entertainment, representing a clean unadulterated joy for the entire family to visit and enjoy. Children are especially enthralled on watching the acts of trapeze, gymnasts, cyclists, acrobats or jokers. Little do they know that this fairy tale world has another face, that the artists performing in front of them are also little children masking their smiles under their heavily made up faces. One side it is joyful but another side it is a sin in our society.

$>$ On the streets- Rag pickers, porters, vendors etc.

$>$ Domestic work- Largely invisible and silent and hence face higher degree of exploitation and abuse in the home of employees. From the fig.3, it may be shown that, as per the census 2001, highest percentage of child was engaged in pan, Bidi and Cigarettes working (20.71\%). Followed construction(17.12\%) ,Domestic workers(15.21\%) ,Others(11.08\%), spinig/weaving (10.57\%), Brickkilns,Tiles (6.96\%), Dhabas/Restaurants/Hotels/motels(5.81\%),Autoworkship,vehicle repairs (4.09\%),Gem-cutting ,Jellellery (3.07\%),Carpet making(2.67\%),Ceramic(1.54\%)and Agarbati, Dhoop and Detergent making (1.11\%).

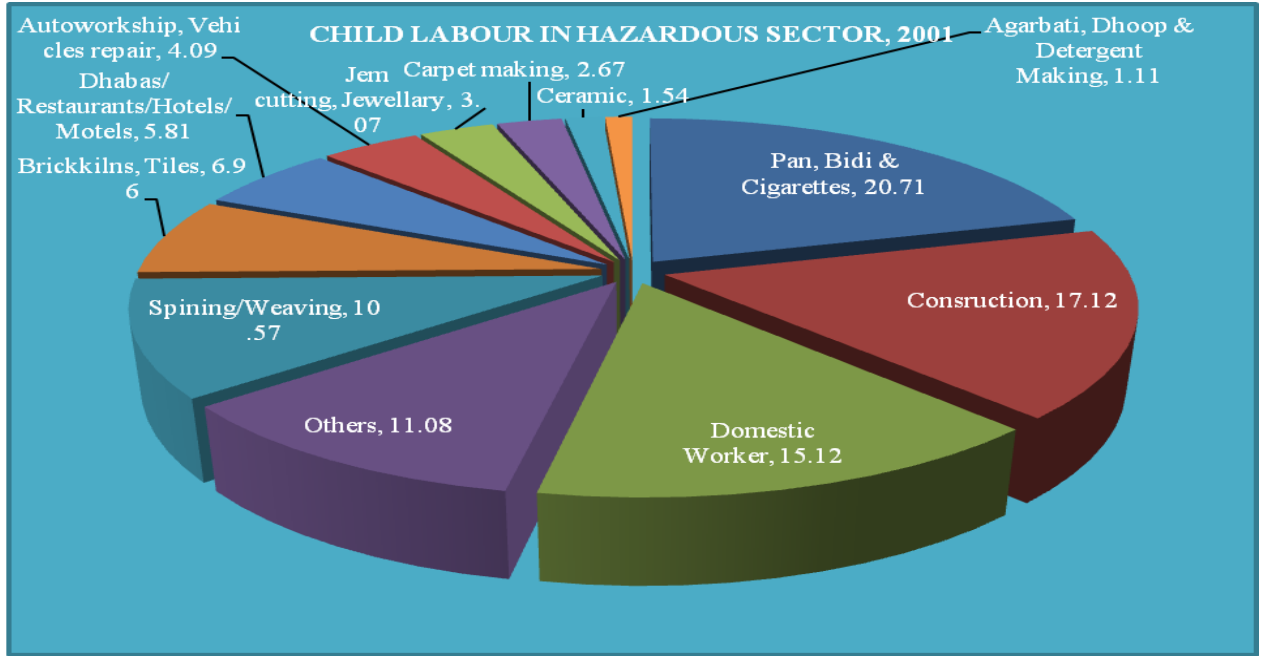

Fig-3; Child working population in India according to 2001 Census.

\section{Effects of Child Worker:}

Child labour is a socio-economic phenomenon. The socio-economic backwardness followed by poverty, illiteracy, unemployment, demographic expansion, deep soul prejudices etc. According to I.L.O it has some impacts in our society, these are; 1) Sexual abuse, 2) Emotional neglect such as deprivation of family loves and affection, resulting in loneliness and hopelessness. 3) Physical neglect. 4) Lack of schooling results in missing educational qualifications.

\section{MAJOR FINDINGS:}

Childhood is the most innocent stage of a human life. It is that phase where a child is free from all the tensions. But at present they are facing number of problems. According to the statistics provided by UNICEF, 
there are an estimated 250 million children aged 5 to 14 years employed in child labour worldwide and this figure is continuously increasing (Agarwal).

- Sikkim had the highest Work Participation Rate (WPR) in the country with $12.04 \%$ child labourers among total children in the age group of 5-14 years, followed by Rajasthan $8.25 \%$ and Himachal Pradesh $(8.14 \%)$ during 2001. The other states having higher than the national average of 5 percent WPR for children are Andhra Pradesh (7.7\%), Chhattisgarh (6.96\%), Karnataka (6.91\%), Madhya Pradesh (6.71\%), J\&K (6.62\%), Arunachal Pradesh (6.06\%), Jharkhand and Assam (5.07\%).

- Notably, at all ages, girls are more likely than boys to be doing chores and boys are more likely than girls to be working for someone who is not a member of the household or doing other family work.

- The very young children (age 5-7 years), both boys and girls, are mainly doing unpaid work for someone who is not a member of their household. The older boys age 12-14 are mainly engaged in paid work or family work, whereas girls in this age group are involved mainly in household chores or family work.

- Children were engaged in their work place every day almost seven days (Barman \& Roy, 2013).The conditions of working children are also pathetic. Most of the migrant children are living in unhygienic conditions.

- There is no limitation of working hours. Actually the work is depending on the nature of work.

- No extra money paid for extra or overtime works.

- Low wages i.e., not enough for a simple living.

- Getting normal food.

- Living unhygienic situation and Lower health improvement.

\section{CHILD LABOUR ACT:}

Children are blooming flowers of the garden of society and valuable asset of a nation. The child labour Act, 1986, was the culmination of efforts and ideas that emerged from deliberations and recommendations of various committees child labour. Significant among them are National Commission on Labour (1966-69), Gurupadaswamy committee on child labour (1979) and Sanat Mehta Committee (1984). The basic objectives of the Act, 1986, are to ban employment of children below the age of 14 years in factories, mines and hazardous employments, and regulate the working conditions of children in other employments.

\section{Recommendations:}

1) Compulsory education has historically been one of the most significant instruments for eliminating child labour practice. School provides children with guidance and opportunity to understand their role in our society .Therefore, many insist on immediately abolishing in developing countries and requiring children to go to school. But it has many problems, such as children will not attend these school without change their economic condition.

2) To prevent the poverty from our society.

3) It should be identify the Below Poverty Level (BPL) families and to help them economically as well as morally.

4) Need different Government programmes as well as NGOs programmes.

5) Government Authorities have to identify all the hazardous sectors and have to take appropriate measures for preventing the child labour in their working place.

\section{References:}

[1]. Barman, Bhupen \& Roy, Ranjan (2013), "Migrant Child Labour in informal Sector of Hotels and Restaurants-A Case Study on Siliguri and adjoining areas", ( $1^{\text {st }}$ edit.), West Bengal. Graphic Printers, pp-109-118.

[2]. Census of India, $2001 \& 2011$.

[3]. CHILDREN IN INDIA 2012 - A Statistical Appraisal, Government of India.

[4]. Ghosh Madhab (2013), 'Child labour and migration in India' ( $1^{\text {st }}$ edit.), West Bengal, Graphic Printers, pp-86-99.

[5]. Human Trafficking ppt. Retrieved from schools.alcdsb.on.cal.../Human\%20Rights\%20Documents/Human\%20Tr

[6]. Kreston, Susan; International Conventions, Protocols and Charters, University of the Free State.

[7]. Mishra, Lakshmidhar.Child Labour in India. New Delhi: Oxford University Press, 2000, 43-44.

[8]. Naidu, M.C., and Ramaiah, K. Dasaratha .Child Labour in India, Journal of Social Science, (2006). 13(3), pp-199-204.

[9]. Sharma, Usha (2003). Child labour in India. New Delhi: Mittal Publications.

[10]. www.childjustice.org/wsecl/papers/Molankal2008.pdf.

[11]. Siddiqi, Faraaz \& Patrinos, and Harry Anthony: Child labour: issues, causes and interventions. Retrieved from www.researchgate.net/...Child_labor...causes.../72e7e5290c93de87ee.pdf

[12]. Noguchi, Yoshie: Children working on the street, IPEC. Retrieved from www.ilo.org/ipec

[13]. Agarwal, Anuj: Child labour-causes and effects. Retrieved from http://anujagarwal.hubpages.com/hub/Cause-and-effects-of-ChildLabour. 